\title{
Expression of fatty acid synthase is regulated by PGC-1 $\alpha$ and contributes to increased cell proliferation
}

\author{
SEONG-HOON YUN ${ }^{*}$, SUNG-WON SHIN ${ }^{*}$ and JOO-IN PARK \\ Department of Biochemistry, Dong-A University College of Medicine, Seo-Gu, Busan 49201, Republic of Korea
}

Received December 27, 2016; Accepted October 4, 2017

DOI: $10.3892 /$ or.2017.6044

\begin{abstract}
We previously demonstrated that overexpression of peroxisome proliferator-activated receptor $\gamma$ coactivator- $1 \alpha$ (PGC-1 $\alpha$ ) promotes increased cell proliferation and tumorigenic potential through upregulation of specificity protein 1 (Sp1) and acyl-CoA-binding protein (ACBP). Fatty acid synthase (FASN) is a key enzyme in fatty acid biosynthesis, and its expression in various cancers is associated with survival, poor prognosis and cancer recurrence. In the present study, we evaluated whether PGC- $1 \alpha$ regulated FASN expression in human colorectal cancer (SNU-C4 and HT-29) cells. We also examined whether cell proliferation was inhibited by shRNA-induced FASN knockdown in SNU-C4 and HT-29 cells. In all tested cell lines, FASN-shRNA knockdown inhibited cell proliferation, decreased antioxidant enzyme expression, and increased apoptosis and production of $\mathrm{H}_{2} \mathrm{O}_{2}$-induced reactive oxygen species (ROS). These findings indicated that FASN expression may enhance cell proliferation by regulating antioxidant enzyme production and resistance to ROS-induced apoptosis. We further provided evidence that FASN expression was regulated indirectly through upregulation of Sp1 and SREBP-1c by PGC-1 $\alpha$. Overall, our results revealed that FASN expression, mediated by PGC-1 $\alpha$, may play a positive role in cancer cell proliferation.
\end{abstract}

\section{Introduction}

Fatty acid synthase (FASN) is a multifunctional enzyme involved in the synthesis of palmitate from acetyl-CoA and malonyl-CoA (1). While FASN is minimally expressed in normal human tissues (2), it exhibits markedly increased expression in several human cancers, and its overexpression in

Correspondence to: Professor Joo-In Park, Department of Biochemistry, Dong-A University College of Medicine, 32 Daesingongwon-ro, Seo-Gu, Busan 49201, Republic of Korea

E-mail: jipark@dau.ac.kr

*Contributed equally

Key words: fatty acid synthase, PGC-1 $1 \alpha$, cell proliferation, reactive oxygen species-induced apoptosis, antioxidant enzyme tumors is associated with poor prognosis (3-6). FASN overexpression induced invasive adenocarcinomas in human prostate epithelial cells. It also protected cells from apoptosis, with FASN expression being inversely associated with the apoptotic rate in human prostate cancer specimens (7). Increased FASN expression was also linked to short-term survival in cases of colorectal and ovarian cancer (3). Increased FASN expression and activity was an early event in the development and progression of lung squamous cell (8) and prostate cancer (9), and melanoma (10). Furthermore, high FASN expression was associated with an overall high proliferative index in prostate cancer (9), and FASN expression intensity was related to prognosis in melanoma (10).

Cerulenin, a natural antibiotic product of the fungus Cephalosporium caerulens (11), inhibited FASN activity and caused apoptotic death of cancer cells in vitro $(12,13)$. The synthetic cerulenin analog C75, a potent FASN inhibitor (14), was also cytotoxic to cancer cells in vitro, and exhibited substantial in vivo antitumor activity against some human cancer xenografts $(15,16)$. Pharmacological inhibition of fatty acid synthesis reportedly caused selective toxicity to cancer cells, and delayed tumor growth induction in vivo and in vitro (17-19). Moreover, specific inhibition of the FASN gene by siRNA led to apoptosis of prostate tumor cells (20). Collectively, these data strongly indicated that de novo lipogenesis plays a substantial role in tumor pathogenesis (21). However, the molecular mechanism underlying the increased FASN expression in cancer is not fully understood.

Peroxisome proliferator-activated receptor $\gamma$ coactivator (PGC)-1 $\alpha$ is a coactivator that regulates multiple metabolic processes through interactions with various transcription factors (22). Recent studies of the PGC- $1 \alpha$ roles in cancer and in metabolic regulation have produced controversial results. Various studies have reported decreased PGC- $1 \alpha$ expression in breast and colon cancer (23-25). Another investigation demonstrated that PGC-1 $\alpha$ overexpression induced apoptosis in ovarian cancer (26). Although PGC-1 $\alpha$ reportedly acts as a tumor suppressor, it can also promote cell growth in prostate cancer (27). Thus, there remains a need for additional studies of PGC-1 $\alpha$. We previously demonstrated that PGC- $1 \alpha$ enhanced cell proliferation and tumorigenesis by upregulation of specificity protein 1 (Sp1) and acyl-CoA-binding protein (ACBP) (28). We further found that PGC-1 $\alpha$ may promote increased production of antioxidant enzymes, including catalase and superoxide dismutase, contributing to 
apoptosis resistance (28). Vock et al reported that FASN is a target molecule of ACBP, based on the downregulation of FASN in ACBP-knockdown cells (29).

Although both FASN and PGC-1 $\alpha$ play roles in several types of cancer cells, the precise molecular mechanism for the interaction between FASN and PGC-1 $\alpha$ has not been clearly elucidated. In the present study, we investigated whether FASN expression was regulated by PGC-1 $\alpha$ and contributed to increased cell proliferation.

\section{Materials and methods}

Cell preparations. We obtained human colorectal cancer (HT-29 and SNU-C4) cells from the Korean Cell Line Bank (Seoul National University, Seoul, Korea). These cell lines were cultured in Dulbecco's modified Eagle's medium (DMEM) supplemented with $10 \%$ fetal bovine serum (FBS), $100 \mathrm{U} / \mathrm{ml}$ penicillin and $100 \mu \mathrm{g} / \mathrm{ml}$ streptomycin (Gibco, Carlsbad, CA, USA). Cultures were maintained at $37^{\circ} \mathrm{C}$ in a humidified atmosphere of $95 \%$ air $/ 5 \% \mathrm{CO}_{2}$.

Materials. We purchased 2',7'-dichlorofluorescein diacetate (DCFDA) and carboxyfluorescein succinimidyl ester (CFSE) from Molecular Probes (Carlsbad, CA, USA). The Annexin V-fluorescein isothiocyanate (FITC) apoptosis detection kit was obtained from BD Biosciences (San Jose, CA, USA). We purchased the following primary antibodies: anti-PGC-1 $\alpha$ (sc-13067), anti-ACBP (sc-30190), anti-superoxide dismutase (SOD)-2 (sc-30080), anti-Sp1 (sc-59) (all from Santa Cruz Biotechnology, Santa Cruz, CA, USA), anti-catalase (ab1877) (Abcam, Cambridge, UK) and anti-FASN (6910962) (BD Biosciences). The anti- $\beta$-actin (A1978), anti-rabbit IgG (A0545) and anti-mouse IgG secondary antibodies (A9044) were purchased from Sigma-Aldrich (St. Louis, MO, USA). Unless otherwise stated, all other chemicals were purchased from Sigma (St. Louis, MO, USA).

Western blot analysis. Cell lysis and western blot analysis were performed as previously described (28). We used $30 \mu \mathrm{g}$ protein for the immunoblotting, and $\beta$-actin was used as the loading control.

Immunofluorescence staining. Cells were cultured on a Lab-Tek ${ }^{\circledR}$ Chamber Slide ${ }^{\mathrm{TM}}$ (Nalge Nunc, Inc., Rochester, NY, USA), and then fixed with $3 \%$ formaldehyde, permeabilized using $0.01 \%$ Triton X-100 and blocked for 30 min with $3 \%$ FBS. Next, the cells were incubated with a primary antibody for $1 \mathrm{~h}$, and then with a fluorescence-labeled secondary antibody (Sigma) for $30 \mathrm{~min}$. The cells were subsequently washed, mounted using glycerol, and analyzed using a Zeiss LSM 510 confocal microscope (Carl Zeiss Co., Ltd., Jena, Germany) with a 40x C-Apochromat objective. Negative control staining was performed with only secondary antibodies.

Promoter reporter constructs and luciferase assays. The FASN promoter construct (30) was provided by Professor Kim Kyung-Sup (Department of Biochemistry and Molecular Biology, Yonsei University, Seoul, Republic of Korea). For the luciferase assay, SNU-C4, HT-29 and FASN shRNA-silenced cells were seeded into a 6 -well plate $\left(1 \times 10^{6}\right.$ cells/well $)$ in
DMEM containing 10\% FBS. After two days, the cells were co-transfected with $1 \mu \mathrm{g}$ FASN promoter-driven luciferase reporter vector and $0.1 \mu \mathrm{g}$ Renilla luciferase control vector, with or without pcDNA3.1 or PGC-1 $\alpha$ expression vector, using Lipofectamine 2000 (Invitrogen, Carlsbad, CA, USA) following the manufacturer's instructions. After a 6-h incubation, the cell medium was replaced with fresh DMEM containing $10 \%$ FBS. After a 24-h incubation, the cells were washed with phosphate-buffered saline (PBS) and harvested in $200 \mu 1$ reporter lysis buffer (Promega, Madison, WI, USA). The cells were vigorously mixed for $15 \mathrm{~min}$, and then centrifuged at $12,000 \mathrm{x} \mathrm{g}$ for $10 \mathrm{~min}$ at $4^{\circ} \mathrm{C}$. The supernatants were transferred into fresh tubes, and $10 \mu \mathrm{g} / \mathrm{ml}$ aliquots of the cleared whole cell lysate were assayed for luciferase activity. Luciferase assays were performed using a Dual-Luciferase Assay kit (Promega) and quantitation was performed with a Lumat LB9501 luminometer. Luciferase activity was normalized by quantitating the protein and adjusting the amount of extract to a fixed amount of protein.

For the siRNA transfection experiment, the cells were seeded into 6-well culture plates and cultured overnight. The cells were first transfected with non-silencing control (NC) siRNA, PGC-1 $\alpha$ siRNA, Sp1 siRNA, SREBP-1c siRNA or both Sp1 siRNA and SREBP-1c siRNA using Lipofectamine 2000. After a 24-h incubation, the cells were co-transfected with FASN promoter-driven reporter constructs and Renilla luciferase vector, with or without pcDNA3.1 or PGC-1 $\alpha$ expression vector, for $24 \mathrm{~h}$. Finally, these cells were collected for use in luciferase assays. All transfections were performed in triplicate, and repeated at least thrice in independent experiments.

siRNA transfection. The siRNA sequence used for targeted silencing of PGC-1 $\alpha$ was designed by Qiagen (GS10891; Valencia, CA, USA). The Sp1 siRNA (SC-29487) and SREBP-1c siRNA (SC-36557) were purchased from Santa Cruz Biotechnology. The cells were resuspended in PBS at a density of $1.3 \times 10^{7}$ cells $/ 0.5 \mathrm{ml}$, and transfected with $4 \mathrm{nM}$ PGC- $1 \alpha$ (4 nM Sp1 or 4 nM SREBP-1c, both Sp1 and SREBP-1c) or NC siRNA using Lipofectamine 2000 following the manufacturer's procedure. After transfection, the cells were cultured in DMEM with $10 \%$ FBS for $48 \mathrm{~h}$. These cells were then used for luciferase assays, immunofluorescence staining, and western blot analysis.

Cell counting. SNU-C4 and HT-29 cells, transfected with shRNA for FASN or with NC shRNA, were seeded into a 6-well plate $\left(1 \times 10^{5}\right.$ cells/well). After 24,48 or $72 \mathrm{~h}$ of incubation, the cells were harvested by trypsinization using trypsin/EDTA, and stained with trypan blue. The vital cells (those not stained with trypan blue) were counted under a Nikon Eclipse TS100 microscope (Nikon, Tokyo, Japan). Three independent experiments were conducted.

Cell proliferation assay. Cell proliferation was assessed using the CFSE labeling assay as previously described (31). Briefly, the cells were washed three times with PBS, and incubated for 15 min with $1 \mu \mathrm{M}$ CFSE dye (Molecular Probes). The cells were then washed again, incubated with fresh medium containing $10 \%$ FBS, and seeded in 6 -well plates ( $1 \times 10^{5}$ cells/well). Cells were incubated for 24,48 or $72 \mathrm{~h}$, and then analyzed using flow 
cytometry (FACSCalibur; BD Biosciences). Each condition was tested in triplicate.

Generation of a FASN-silenced cell line. An shRNA construct containing FASN shRNA (MISSION ${ }^{\circledR}$ shRNA plasmid DNA; FASN-pLKO.1-puro) and a non-targeting control construct (NC-pLKO.1-puro) were provided by Sigma. The sequences were as follows: FASN shRNA, 5'-CCGGCATGGAGCGTAT CTGTGAGAACTCGAGTTCTCACAGATACGCTCCATGT TTTT-3'; NC shRNA, 5'-GCGCGATAGCGCTAATAAT TT-3'. SNU-C4, and HT-29 cells $\left(1 \times 10^{6}\right)$ were transfected with $2 \mu \mathrm{g}$ of FASN-pLKO.1-puro or NC-pLKO.1-puro using Lipofectamine 2000, following the manufacturer's procedure. At $48 \mathrm{~h}$ post-transfection, the cells were incubated with $2 \mu \mathrm{g} / \mathrm{ml}$ puromycin for 14 days to select stable clones. Positive clones were chosen for identification, and cultured in DMEM supplemented with $10 \% \mathrm{FBS}, 2 \mu \mathrm{g} / \mathrm{ml}$ puromycin, $100 \mathrm{U} / \mathrm{ml}$ penicillin and $100 \mu \mathrm{g} / \mathrm{ml}$ streptomycin (Gibco). Cultures were maintained at $37^{\circ} \mathrm{C}$ in a humidified atmosphere of $95 \%$ air $/ 5 \% \mathrm{CO}_{2}$.

Annexin V-PI staining assay. The extent of apoptosis was evaluated using Annexin V-FITC and flow cytometry as previously described (32).

Assessment of ROS production. ROS production was monitored by flow cytometry using carboxy- $\mathrm{H}_{2}$ DCFDA (Molecular Probes). FASN-silenced SNU-C4 and HT-29 cells were washed twice with PBS to remove extracellular compounds. FASN-silenced SNU-C4 and HT-29 cells were transfected with pReceiver-M13 (EX-M13) or FASN expression vector (pReceiver-M13-FASN; EX-T3050-M13) (both from GeneCopoeia, Rockville, MD, USA) and treated with PBS or $\mathrm{H}_{2} \mathrm{O}_{2}$ and then washed twice with PBS to remove extracellular compounds. Next, the cells were incubated for an hour with $\mathrm{H}_{2}$ DCFDA $(100 \mu \mathrm{mol} / \mathrm{l})$. Finally, for flow cytometric analysis, green fluorescence was excited using an argon laser and detected using a 525-nm band-pass filter.

Statistical analysis. Statistical analyses were performed using the SPSS 22.0 statistical package for Windows (SPSS, Inc., Chicago, IL, USA). Data are expressed as mean \pm standard deviation (SD). One-way analysis of variance (ANOVA) was used to evaluate whether cell viability significantly differed between FASN-silenced and control cells. Statistical significance was defined as $\mathrm{P}<0.05$.

\section{Results}

FASN is upregulated in colorectal cancer cell lines that overexpress $P G C$ - $1 \alpha$. Prior studies have demonstrated an association between FASN overexpression in tumors and proliferation (33-35), and we previously revealed that PGC-1 $\alpha$ overexpression enhanced cell proliferation (28). To investigate the relationship between FASN and PGC-1 $\alpha$ expression, we used western blotting and immunofluorescence staining to examine FASN and PGC-1 $\alpha$ expression in HT-29 and SNU-C4 cells. The FASN and PGC-1 $\alpha$ proteins were expressed at slightly lower levels in HT-29 cells compared to SNU-C4 cells (Fig. 1A and C). We previously reported that knockdown of PGC-1 $\alpha$ expression in human colorectal cancer cells led to decreased cell proliferation (28). To determine whether FASN contributed to the PGC- $1 \alpha$ role in cell proliferation, we used western blotting and immunofluorescence staining to observe FASN expression in PGC-1 $\alpha$ siRNA-transfected cells. We found that PGC-1 $\alpha$ siRNA-transfected SNU-C4 and HT-29 cells showed decreased FASN expression (Fig. 1B and D), suggesting that FASN expression was related to PGC-1 $\alpha$ expression.

FASN expression is regulated through upregulation of Spl and SREBP-1c by PGC-1 $\alpha$. To investigate whether FASN expression was regulated by PGC-1 $\alpha$, we performed a luciferase assay in SNU-C4 and HT-29 cells that were co-transfected with the PGC-1 $\alpha$ expression vector and a FASN promoter-driven luciferase plasmid. As shown in Fig. 2A, FASN promoter activity was significantly increased by PGC-1 $\alpha$ expression in SNU-C4 and HT-29 cells, by 3.03- and 2.72-fold, respectively (Fig. 2A). We further confirmed that PGC- $1 \alpha$-siRNA transfection reduced the PGC-1 $\alpha$-induced increase in FASN promoter activity (Fig. 2B).

Previous studies revealed that the promoter activity of FASN was regulated by binding of Sp1 and SREBP-1c to the FASN promoter (36). We previously have shown that the expression of Sp1 was enhanced by PGC-1 $\alpha$ expression (28). In the present study we observed that PGC-1 $\alpha$ expression increased Sp1 and SREBP-1c expression (Fig. 2C). We also observed that PGC-1 $\alpha$-siRNA transfection decreased the Sp-1 and SREBP-1c expression (Fig. 2C). We evaluated whether the enhanced FASN promoter activity by PGC-1 $\alpha$ was mediated through Sp1 and SREBP-1c using siRNA transfection with Sp1 siRNA, SREBP-1c siRNA or both Spl and SREBP-1c siRNA. As shown in Fig. 2D, the increased FASN promoter activity was decreased by Sp1 siRNA, SREBP-1c siRNA or both Sp1 siRNA and SREBP-1c siRNA even with the presence of PGC-1 $\alpha$. These data revealed that the promoter activity of FASN may be regulated indirectly through upregulation of Sp1 and SREBP-1c.

FASN knockdown reduces cell proliferation in SNU-C4 and HT-29 cells. We next evaluated the functional significance of FASN expression in the growth of SNU-C4 and HT-29 cells. These cell lines were transfected with FASN shRNA or with NC shRNA, and then cultured with G418 for 14 days. Next, several colonies were chosen and amplified. FASN knockdown was detected by western blot analysis with an antibody against FASN. Compared to the corresponding control cells, FASN protein levels were, respectively, 72 and $78 \%$ (SNUC4) lower in the SNU-C4-FASN shRNA-1 and -3 cells, and 78 and $80 \%$ (HT-29) lower in the HT-29-FASN shRNA-2 and -3 cells, respectively (Fig. 3A).

To investigate whether FASN knockdown affected cell growth in human SNU-C4 and HT-29 cells, we assessed cell proliferation by cell counting and CFSE labeling assays. At $72 \mathrm{~h}$, the SNU-C4-FASN shRNA-1 and -3 cells exhibited cell numbers that were, respectively, 32 and $34 \%$ lower than that of the SNU-C4-control cells (Fig. 3B; P<0.001), and the HT-29-FASN shRNA-2 and -3 cell numbers were, respectively, 34 and $37 \%$ lower than that of the HT-29-control cells (Fig. 3B; P<0.001). As aforementioned, CFSE labeling analysis confirmed that FASN knockdown also decreased cell proliferation in SNU-C4 and 
A

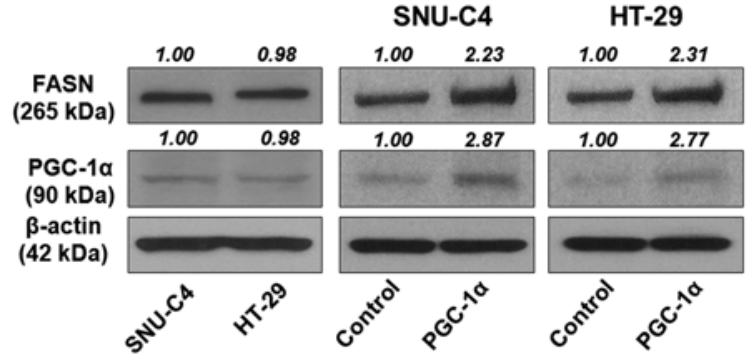

B

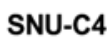

HT-29

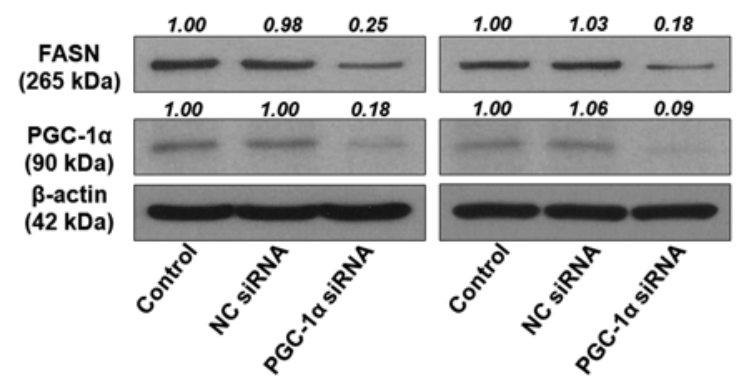

C SNU-C4

HT-29

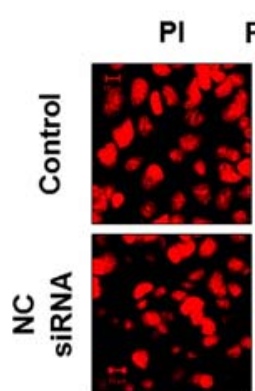

PGC-1a-FITC Merged
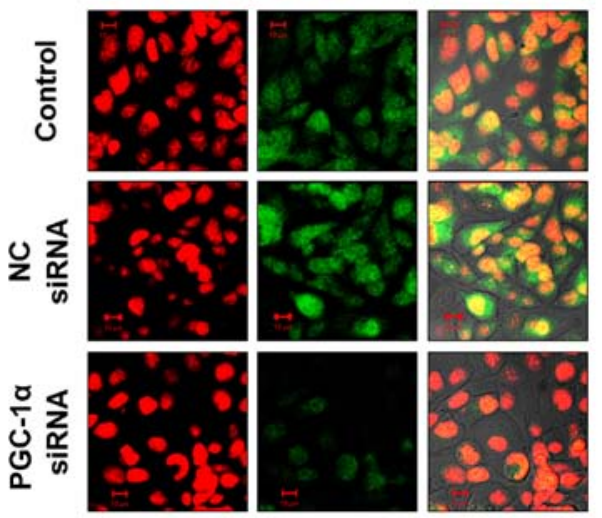

SNU-C4

D
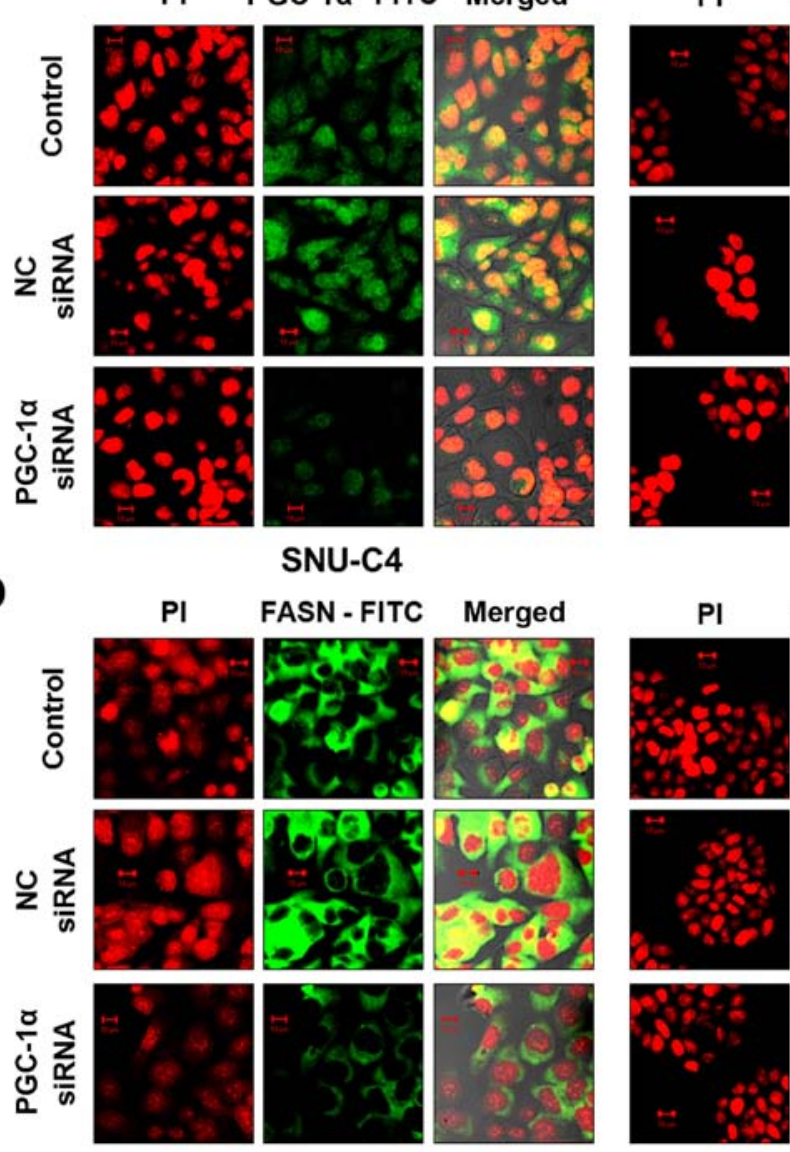

PGC-1 $\alpha$-FITC Merged
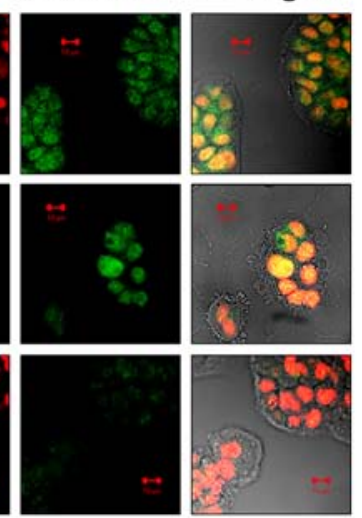

HT-29

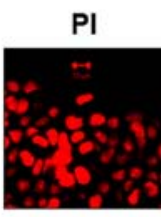

FASN - FITC
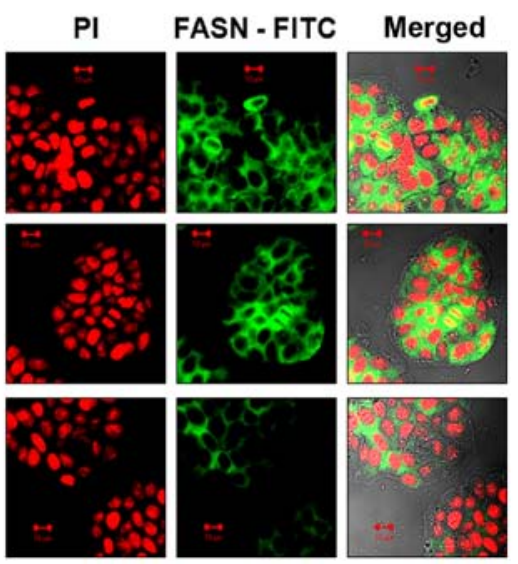

Figure 1. FASN expression is regulated by PGC-1 $\alpha$. (A and B) Western blot analysis of FASN and PGC-1 $\alpha$ in SNU-C4 and HT-29 cells (A). (B) SNU-C4 and HT-29 cells were transfected with non-specific control (NC) or PGC-1 $\alpha$-specific siRNAs. At $72 \mathrm{~h}$ post-transfection, the protein levels of PGC-1 $\alpha$ and FASN were analyzed by western blotting using anti-PGC-1 $\alpha$ or anti-FASN antibodies. Anti-FASN and anti-PGC-1 $\alpha$ antibodies were used, and $\beta$-actin was probed for equal protein loading. Densitometry results are expressed above the bands. (C and D) SNU-C4 and HT-29 cells were transfected with non-specific control (NC) or PGC-1 $\alpha$-specific siRNAs. At $72 \mathrm{~h}$ post-transfection, immunofluorescence staining was performed using (C) anti-PGC-1 $\alpha$ and (D) anti-FASN antibodies (green) in control, NC siRNA and PGC-1 $\alpha$ siRNA-transfected SNU-C4 and HT-29 cells. Nuclei were stained with PI.

HT-29 cells (Fig. 3C). However, the protein levels of PGC-1 $\alpha$ were not downregulated in FASN shRNA-transfected SNU-C4 and HT-29 cells (Fig. 3A). These data indicated that FASN acts downstream of PGC-1 $\alpha$ in the regulation of cell proliferation. 
A

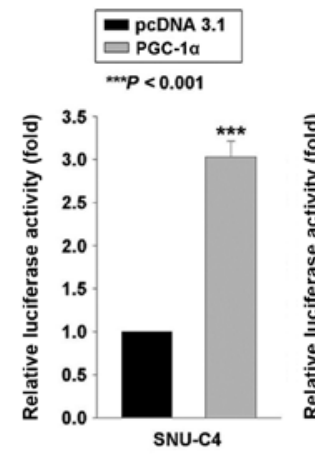

B

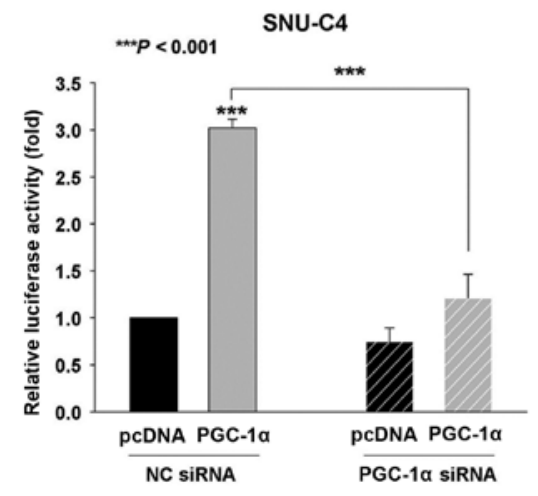

C

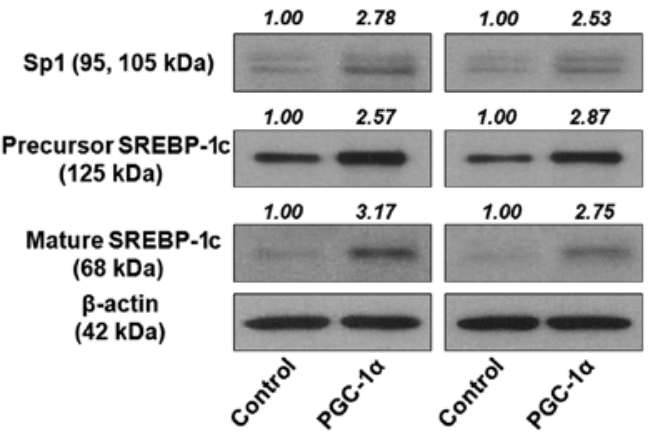

D

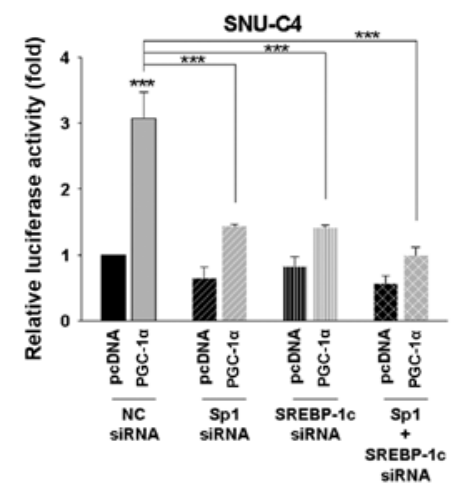

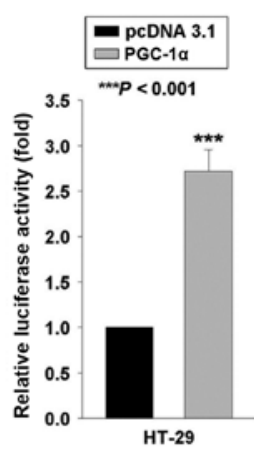

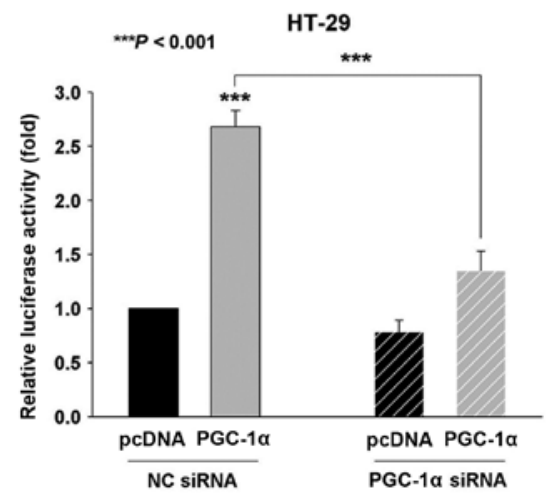

SNU-C4

HT-29
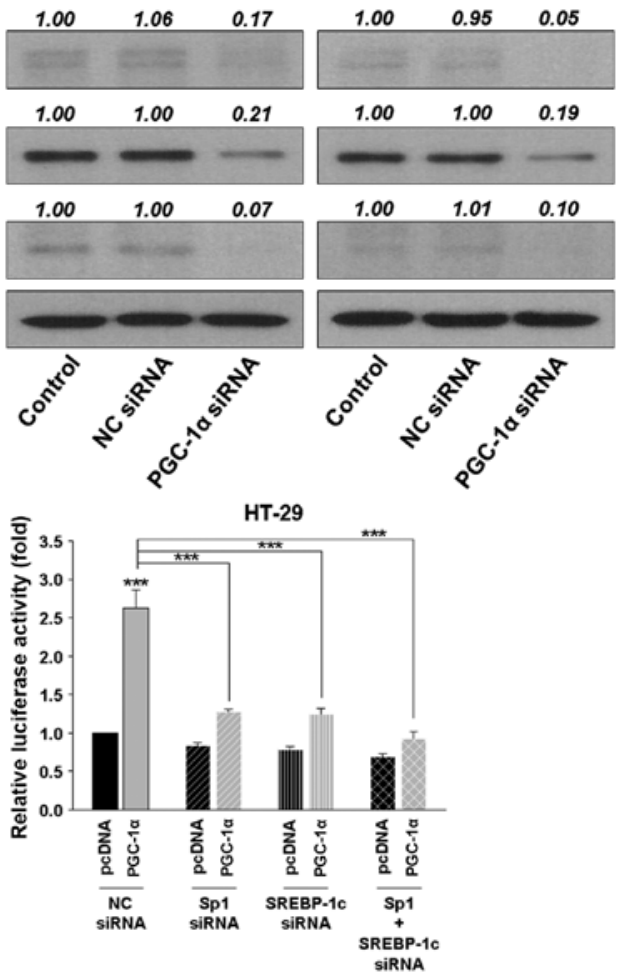

Figure 2. FASN promoter activity is regulated through Sp1 and SREBP-1c by PGC-1 $\alpha$. (A) PGC-1 $\alpha$ enhanced FASN promoter activity in SNU-C4 and HT-29 cells. All cell lines were co-transfected for $24 \mathrm{~h}$ with the FASN promoter-driven luciferase reporter plasmid and Renilla luciferase control vector, as well as the pcDNA3.1 or PGC-1 $\alpha$ expression vector. Results are presented as normalized relative luciferase activity ( $\mathrm{n}=3$ ). (B) Enhanced FASN promoter activity was reversed by PGC-1 $\alpha$ siRNA transfection. SNU-C4 and HT-29 cells were transfected for $24 \mathrm{~h}$ with NC siRNA or PGC-1 $\alpha$ siRNA. Next, the cells were co-transfected for $24 \mathrm{~h}$ with the FASN promoter-driven luciferase reporter plasmid and Renilla luciferase control vector, as well as the pcDNA3.1 or PGC-1a expression vector. Results are presented as normalized relative luciferase activity $(n=3)$. Results are the average of three independent experiments, with statistical significance measured using a t-test $\left.{ }^{(* * *} \mathrm{P}<0.001\right)$. (C, left panel) SNU-C4 and HT-29 cells were transfected with the empty vector (pcDNA 3.1) or PGC-1 $\alpha$ expression vector. (C, right panel) SNU-C4 and HT-29 cells were transfected with non-specific control (NC) or PGC-1 $\alpha$-specific siRNAs. At $72 \mathrm{~h}$ post-transfection, Sp1 and SREBP-1c protein levels were analyzed by western blotting using anti-Sp1 or anti-SREBP-1c antibodies. $\beta$-actin was probed for equal protein loading. Densitometry results are expressed above the bands. (D) Enhanced FASN promoter activity was reversed by Sp1, SREBP-1c or both Sp1 and SREBP-1c siRNA transfection. SNU-C4 and HT-29 cells were transfected for $24 \mathrm{~h}$ with NC siRNA, Sp1, SREBP-1c or both Sp1 and SREBP-1c siRNA. Next, the cells were co-transfected for $24 \mathrm{~h}$ with the FASN promoter-driven luciferase reporter plasmid and Renilla luciferase control vector, as well as the pcDNA3.1 or PGC-1 $\alpha$ expression vector. Results are presented as normalized relative luciferase activity $(\mathrm{n}=3)$. Results are the average of three independent experiments, with statistical significance measured using a t-test $\left.{ }^{* * * *} \mathrm{P}<0.001\right)$. 
A

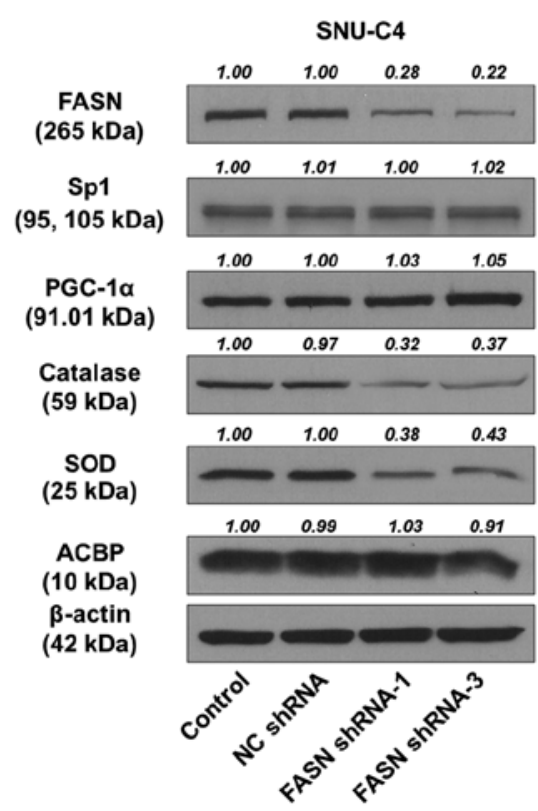

B

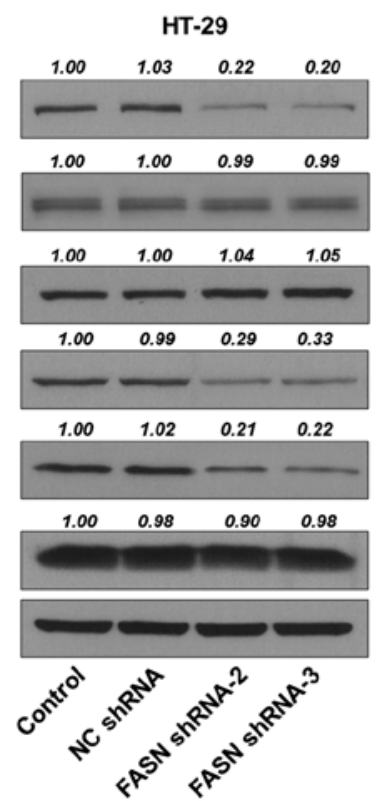

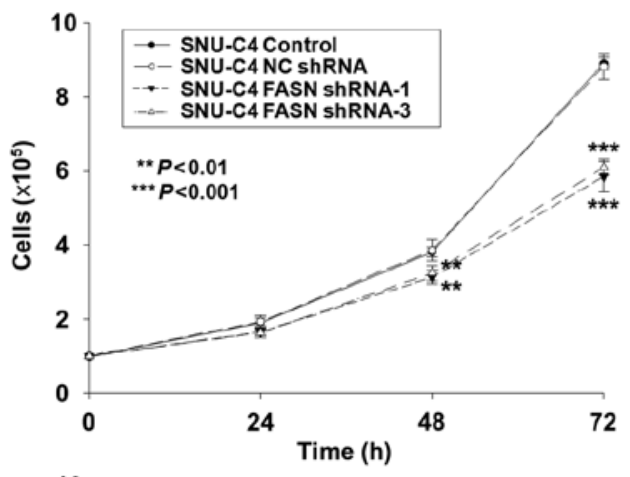

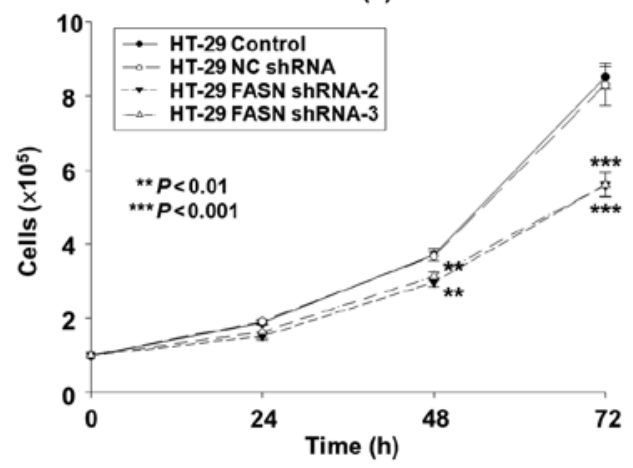

C

$\mathbf{O h}$
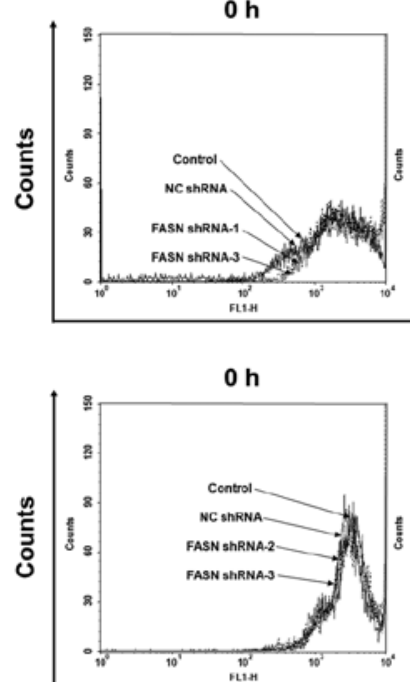

$24 \mathrm{~h}$

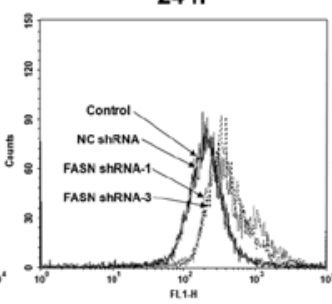

$48 \mathrm{~h}$

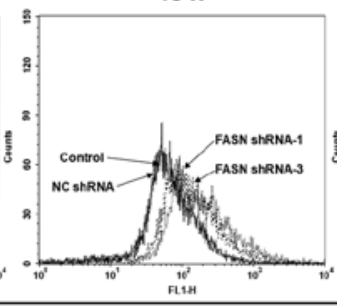

$72 \mathrm{~h}$

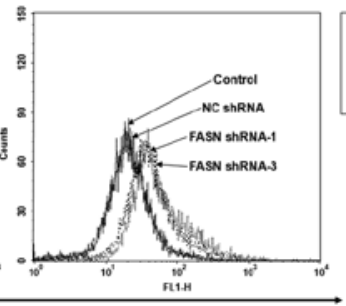

$72 \mathrm{~h}$

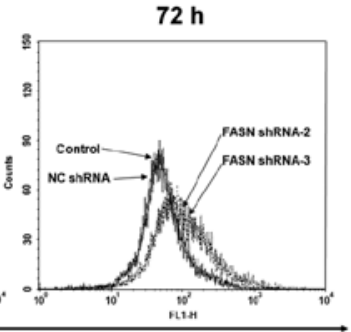

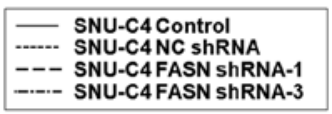

$48 \mathrm{~h}$
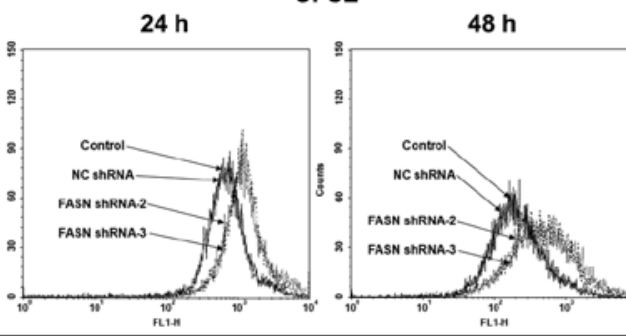

CFSE

Figure 3. FASN knockdown significantly decreases the proliferation of SNU-C4 and HT-29 cells. Using Lipofectamine, SNU-C4 and HT-29 cells were stably transfected with no shRNA (control), non-specific control (NC) shRNA, or shRNA for FASN. (A) Whole-cell lysates were prepared from SNU-C4 and HT-29 cells, and used for western blot analysis to determine FASN, Sp1, PGC-1 $\alpha$, catalase, SOD and ACBP protein expression. Band densities were assessed by densitometric analysis. Data are expressed as the fold change in protein expression normalized to $\beta$-actin expression, with respect to the control and NC shRNA. (B) SNU-C4 and HT-29 cells were stably transfected with FASN shRNA or NC shRNA, and then studied at 24-h intervals for $72 \mathrm{~h}$ after replating. Cell proliferation was determined by cell counting. ${ }^{* *} \mathrm{P}<0.01$ and ${ }^{* * * *} \mathrm{P}<0.001$, vs. the control or NC shRNA-transfected cells. (C) CFSE-labeled cells (1x10 cells/well) were incubated with fresh medium containing $10 \%$ FBS for the indicated times. The samples were analyzed by flow cytometry using a FACScan flow cytometer. Data were analyzed using CellQuest software (BD Biosciences).

FASN downregulation increases sensitivity to $\mathrm{H}_{2} \mathrm{O}_{2}$-induced apoptosis. We previously demonstrated that PGC-1 $\alpha$ induced catalase and SOD, and decreased ROS production, resulting in decreased sensitivity to $\mathrm{H}_{2} \mathrm{O}_{2}$-induced apoptosis and enhanced cell proliferation (28). In the present study, we evaluated the role of FASN in regulating sensitivity to $\mathrm{H}_{2} \mathrm{O}_{2}$-induced apoptosis, by assessing the extent of $\mathrm{H}_{2} \mathrm{O}_{2}$-induced apoptosis and ROS levels in SNU-C4 and HT-29 cells transfected with FASN shRNA or NC control shRNA. The FASN shRNA-transfected SNU-C4 and HT-29 cells exhibited a significantly greater extent of $\mathrm{H}_{2} \mathrm{O}_{2}$-induced apoptosis and ROS level compared to control SNU-C4 and HT-29 cells (Fig. 4B and C). Moreover, the expressions of SOD and catalase (except PGC-1 $\alpha$, Sp1 and ACBP) were decreased by FASN shRNA knockdown in SNU-C4 and HT-29 cells (Fig. 4A).

These data revealed that FASN acts downstream of PGC-1 $\alpha$, Sp1 and ACBP in the regulation of ROS-induced apoptosis and ROS production. Additionally, our results indicated that FASN protected SNU-C4 and HT-29 cells from oxidative stress, such as $\mathrm{H}_{2} \mathrm{O}_{2}$. Increased susceptibility to 


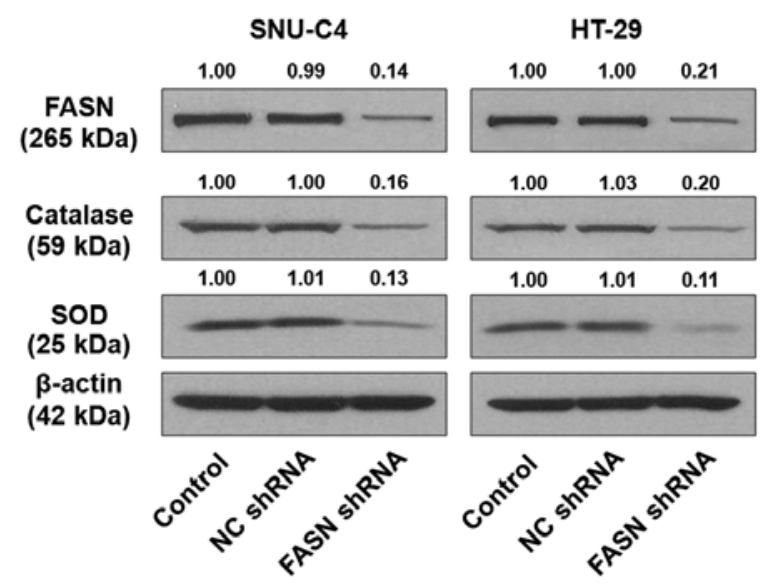

B

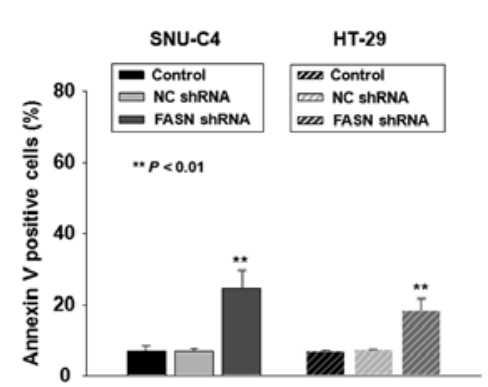

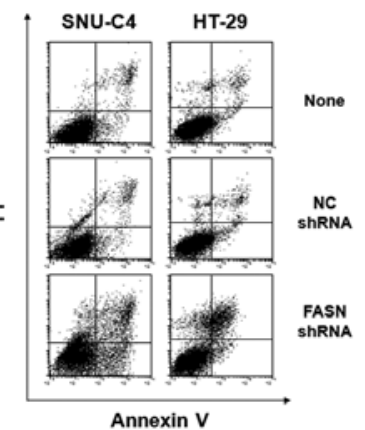

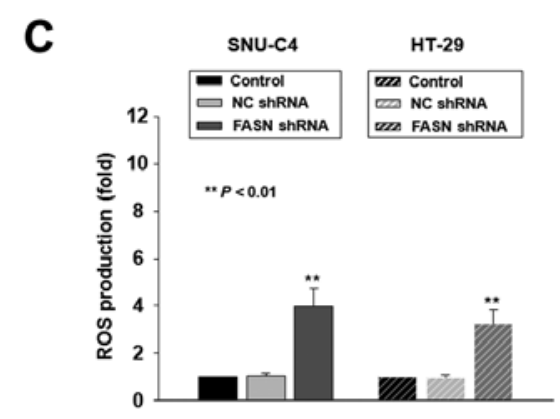

Figure 4. FASN knockdown increases sensitivity to $\mathrm{H}_{2} \mathrm{O}_{2}$-induced apoptosis. (A) SNU-C4 and HT-29 cells were stably transfected with no shRNA (control), non-specific control (NC) shRNA, or FASN shRNA. Whole-cell lysates were prepared from SNU-C4 and HT-29 cells, and used for western blot analysis to determine FASN, catalase and SOD expression. Band densities were assessed by densitometric analysis. Data are expressed as the fold change in protein expression normalized to $\beta$-actin expression, with respect to the control and NC shRNA. (B, left panel) Control, NC shRNA-silenced and FASN shRNAsilenced SNU-C4 cells and control, NC shRNA-silenced, and FASN shRNA-silenced HT-29 cells were treated for $24 \mathrm{~h}$ with $0.5 \mathrm{mM} \mathrm{H}_{2} \mathrm{O}_{2}$, stained with FITC-Annexin V/PI, and analyzed by flow cytometry. Annexin V-positive cells were considered apoptotic. (B, right panel) Representative flow cytometric data of three independent experiments. (C) Control, NC shRNA-silenced, and FASN shRNA-silenced SNU-C4 cells and control, NC shRNA-silenced, and FASN shRNA-silenced HT-29 cells were treated for $24 \mathrm{~h}$ with $0.5 \mathrm{mM} \mathrm{H}_{2} \mathrm{O}_{2}$, and labeled with carboxy- $\mathrm{H}_{2}$ DCFDA. Then, ROS levels were quantified by flow cytometry. Data represent the mean $\pm \mathrm{SD}$ of three independent experiments; ${ }^{* *} \mathrm{P}<0.01$, vs. the control or NC shRNA-transfected cells.

ROS-induced apoptosis may contribute to the decreased cell proliferation observed following FASN shRNA knockdown in SNU-C4 and HT-29 cells. To confirm whether FASN expression regulate the expression of catalase and SOD and ROS-induced apoptosis, FASN shRNA-silenced SNU-C4 and HT-29 cells were transfected with pReceiver-M13 or pReceiver-M13-FASN expression vector, and then treated with $\mathrm{H}_{2} \mathrm{O}_{2}$. The results revealed the decreased expression of catalase and SOD by FASN knockdown was reversed by FASN expression (Fig. 4D). Increased ROS production and $\mathrm{H}_{2} \mathrm{O}_{2}$-induced apoptosis by FASN knockdown were also reversed by FASN expression (Fig. 4E and F). Overall, these results revealed that FASN enhanced cell proliferation and decreased $\mathrm{H}_{2} \mathrm{O}_{2}$-induced apoptosis through upregulation of catalase and SOD in SNU-C4 and HT-29 cells.

\section{Discussion}

In the present study, we found that FASN expression and promoter activity were increased by PGC-1 $\alpha$ expression in SNU-C4 and HT-29 cells. To confirm that this increased FASN promoter activity was caused by PGC- $1 \alpha$ itself, we performed a knockdown experiment using PGC-1 $\alpha$ siRNA. FASN promoter activity was significantly decreased by PGC- $1 \alpha$ knockdown experiments in SNU-C4 and HT-29 cells. These results provide the first evidence that FASN promoter activity was enhanced by PGC-1 $\alpha$ expression in colorectal cancer cells. To evaluate the molecular mechanism for increased FASN promoter activity by PGC-1 $\alpha$, the Sp1 siRNA, SREBP-1c siRNA or both Sp1 and SREBP-1c siRNA knockdown experiments were performed. The results revealed that the increased FASN promoter activity by PGC- $1 \alpha$ was decreased by Sp1 siRNA, SREBP-1c siRNA or both Sp1 siRNA and SREBP-1c siRNA. These data indicated that the enhanced FASN promoter activity by PGC-1 $\alpha$ may be regulated indirectly through $\mathrm{Sp1}$ and SREBP-1c. Despite differences in the utilized cell lines, our data were similar to previous results demonstrating that PGC-1 $\alpha$ enhances lipogenesis in skeletal muscle through liver $\mathrm{X}$ receptor $\alpha(\mathrm{LXR} \alpha)$-dependent activation of the FASN promoter and by increasing FASN activity (37). However, we did not examine whether LXR $\alpha$ was involved in the PGC-1 $\alpha$ mediated regulation of the FASN promoter. Further studies are required to evaluate the possible involvement of $\operatorname{LXR} \alpha$ in the PGC-1 $\alpha$-mediated regulation of FASN promoter activity in colorectal cancer cells.

PGC-1 $\alpha$ overexpression enhanced cell proliferation and tumorigenesis through the increased expression of Sp1 and ACBP in HEK293 cells, and FASN overexpression reportedly promoted cancer growth and metastasis (38-41). Increased FASN may confer a cell survival advantage due to apoptosis 


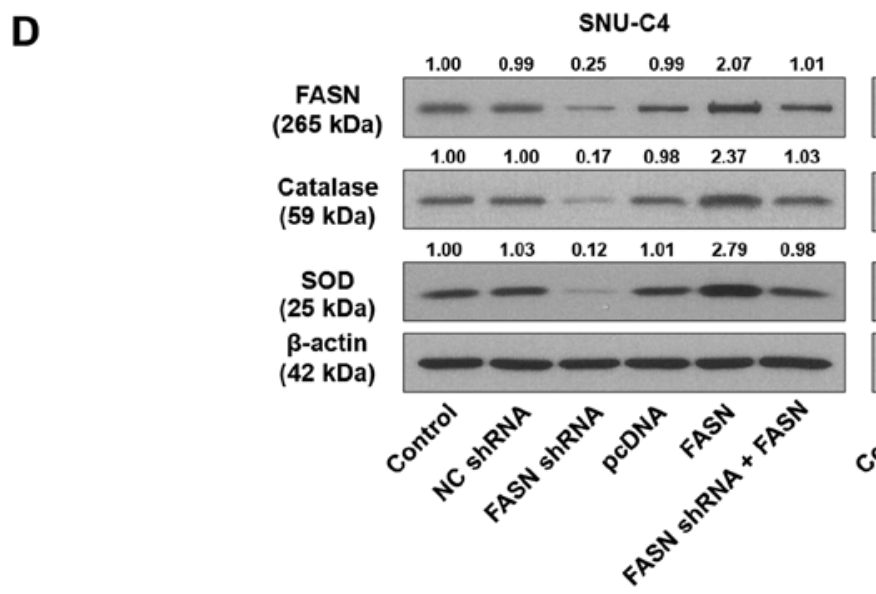

E
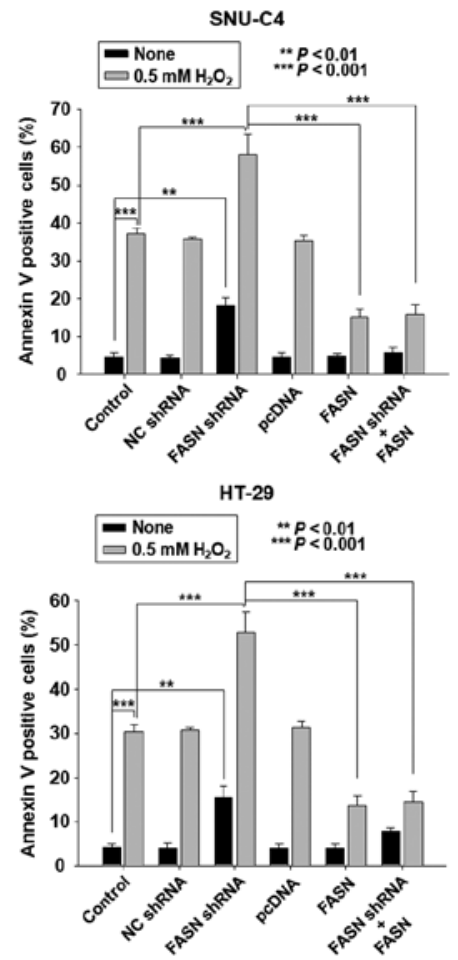

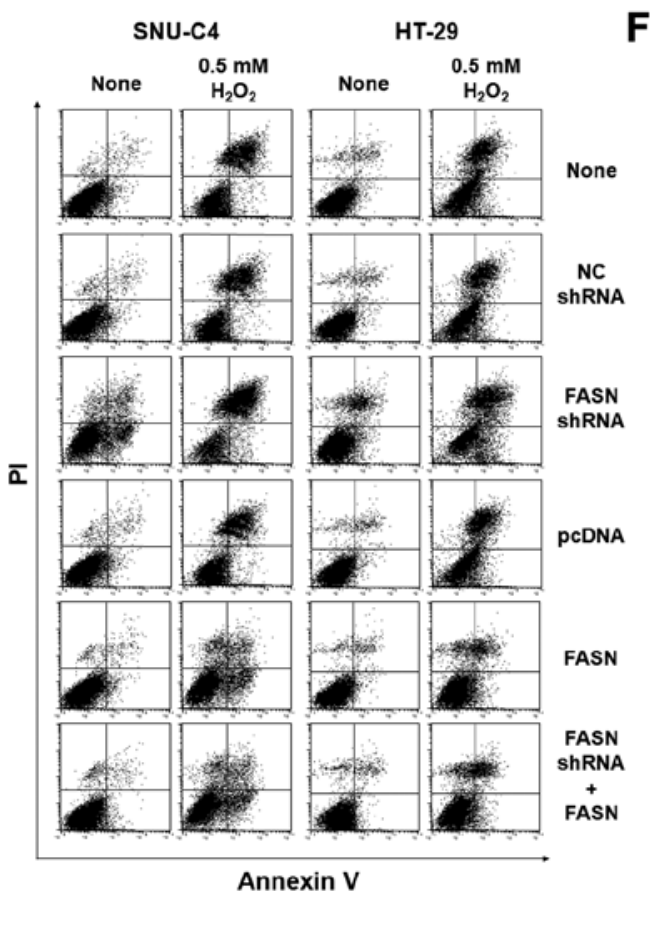

F
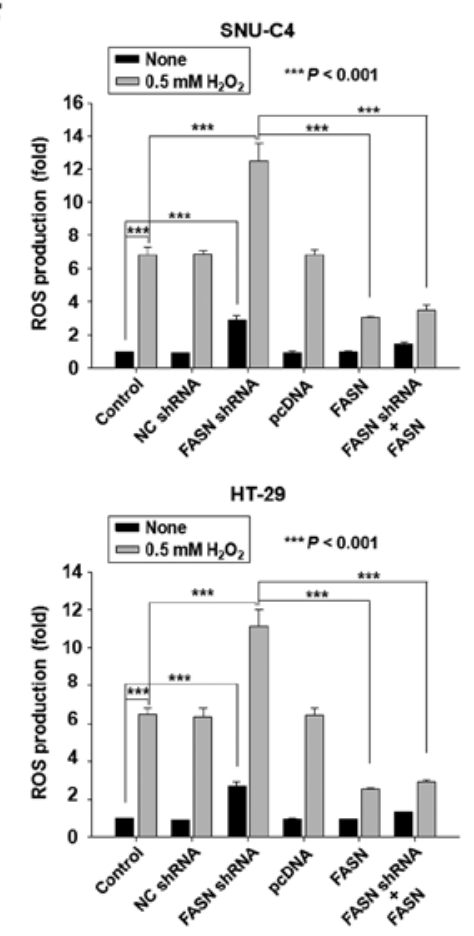

Figure 4. Continued. (D-F) SNU-C4 and HT-29 cells were stably transfected with no shRNA (control), non-specific control (NC) shRNA, or FASN shRNA, and transfected with pcDNA or FASN cDNA expression vector. (D) Whole-cell lysates were used for western blot analysis to determine FASN, catalase and SOD expression. Band densities were assessed by densitometric analysis. Data are expressed as the fold change in protein expression normalized to $\beta$-actin expression, with respect to the control and NC shRNA. (E, left panel) Control, NC shRNA-silenced and FASN shRNA-silenced cells (SNU-C4 and HT-29) and pcDNAtransfected control, FASN cDNA-transfected and FASN cDNA-transfected FASN shRNA-silenced cells (SNU-C4 and HT-29) were treated for 24 h with $0.5 \mathrm{mM} \mathrm{H}_{2} \mathrm{O}_{2}$, stained with FITC-Annexin V/PI, and analyzed by flow cytometry. Annexin V-positive cells were considered apoptotic. ${ }^{* *} \mathrm{P}<0.01$ and ${ }^{* * *} \mathrm{P}<0.001$, vs. the control or NC shRNA-transfected cells. (E, right panel) Representative flow cytometric data of three independent experiments. (F) Control, NC shRNAsilenced, and FASN shRNA-silenced cells (SNU-C4 and HT-29) and pcDNA-transfected control, FASN cDNA-transfected and FASN cDNA-transfected FASN shRNA-silenced cells (SNU-C4 and HT-29) were treated for $24 \mathrm{~h}$ with $0.5 \mathrm{mM} \mathrm{H}_{2} \mathrm{O}_{2}$, and labeled with carboxy-H $\mathrm{H}_{2}$ DCFDA. Then, the ROS levels were quantified by flow cytometry. Data represent the mean \pm SD of three independent experiments; ${ }^{* * *} \mathrm{P}<0.001$, vs. the control or NC shRNA-transfected cells.

resistance, with associated tumor aggressiveness, increased metastasis and poor prognosis (7). Previous data revealed that specific knockdown of either acetyl-CoA carboxylase $\alpha$ (a key enzyme in fatty acid synthesis) or FASN genes in cancer cells led to substantially decreased palmitic acid synthesis. Palmitic acid depletion was associated with apoptosis induction concomitant with ROS formation and mitochondrial impairment (42). Our present results demonstrated that FASN expression was decreased by PGC-1 $\alpha$ siRNA transfection, and that FASN knockdown significantly inhibited cell proliferation and decreased the expression of catalase and SOD, resulting in increased ROS and $\mathrm{H}_{2} \mathrm{O}_{2}$-induced apoptosis in SNU-C4 and HT-29 cells. These findings revealed that PGC-1 $\alpha$ loss was protective against carcinogenesis, and that PGC- $1 \alpha$ coordinately regulated mitochondrial and fatty acid metabolism to promote tumor growth (43).

In conclusion, the present study revealed that FASN expression was indirectly regulated through upregulation of Sp1 and SREBP-1c by PGC-1 $\alpha$, and may contribute to enhanced cell proliferation due to increased antioxidant enzyme expression and resistance to ROS-induced apoptosis. Based on our results, we suggest hypothetical molecular mechanisms 


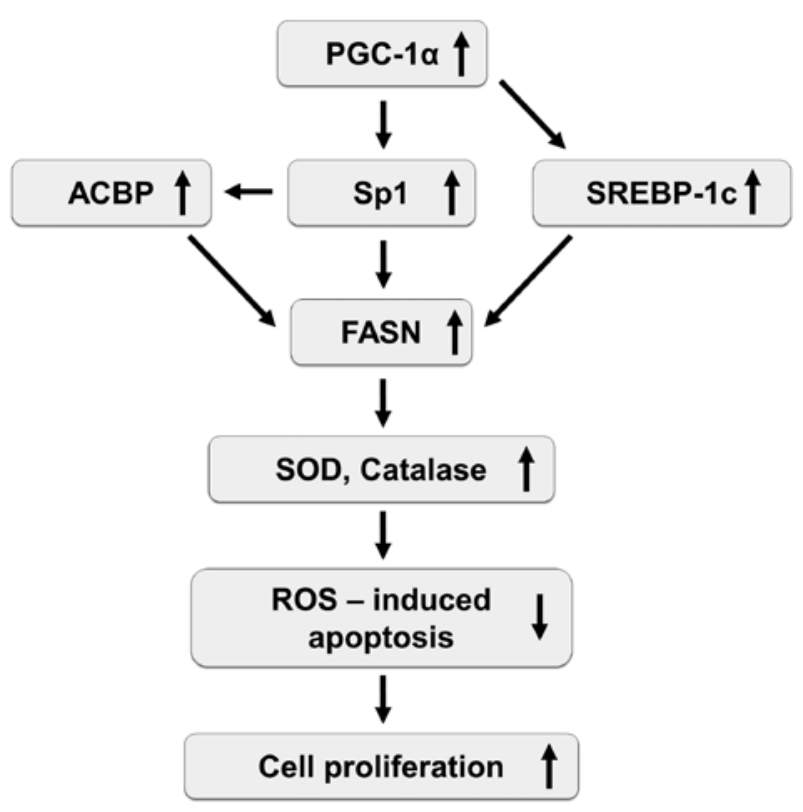

Figure 5. Hypothetical molecular mechanisms by which FASN and PGC-1 $\alpha$ increase cell proliferation. Briefly, FASN expression may lead to increased cell proliferation in a manner related to PGC- $1 \alpha$ and associated with ACBP upregulation through increased $\mathrm{Sp} 1$ expression. The promoter activity of FASN was indirectly increased through upregulation of Sp1 and SREBP-1c by PGC-1 $\alpha$. Moreover, SOD and catalase expression was increased, inhibiting ROS-induced apoptosis and ultimately promoting cell proliferation.

behind the enhancement of cell proliferation by FASN and PGC-1 $\alpha$ (Fig. 5). However, further studies, in greater detail are needed to clarify the mechanisms involved in the regulation of cell proliferation and tumorigenesis. Our results revealed that PGC-1 $\alpha$ and FASN may be useful targets for colorectal cancer treatment. To determine the clinical relevance of the PGC- $1 \alpha$-mediated regulation of FASN expression in these cell lines, it is necessary to investigate the correlation between PGC-1 $\alpha$ and FASN expression in specimens from human colorectal cancer patients.

\section{Acknowledgements}

The present study was supported by the National Research Foundation of Korea (NRF), funded by the Korean Government (MSIP) (no. 2016R1A5A2007009), and by the Basic Science Research Program through the National Research Foundation of Korea (NRF) funded by the Ministry of Science, ICT and Future Planning (2017R1A2B4011428).

\section{References}

1. Little JL and Kridel SJ: Fatty acid synthase activity in tumor cells. Subcell Biochem 49: 169-194, 2008.

2. Kusakabe T, Maeda M, Hoshi N, Sugino T, Watanabe K, Fukuda T and Suzuki T: Fatty acid synthase is expressed mainly in adult hormone-sensitive cells or cells with high lipid metabolism and in proliferating fetal cells. J Histochem Cytochem 48: 613-622, 2000.

3. Gansler TS, Hardman W III, Hunt DA, Schaffel S and Hennigar RA: Increased expression of fatty acid synthase (OA-519) in ovarian neoplasms predicts shorter survival. Hum Pathol 28: 686-692, 1997.

4. Takahiro T, Shinichi K and Toshimitsu S: Expression of fatty acid synthase as a prognostic indicator in soft tissue sarcomas. Clin Cancer Res 9: 2204-2212, 2003.
5. Rossi S, Graner E, Febbo P, Weinstein L, Bhattacharya N, Onody T, Bubley G, Balk S and Loda M: Fatty acid synthase expression defines distinct molecular signatures in prostate cancer. Mol Cancer Res 1: 707-715, 2003.

6. Menendez JA and Lupu R: Fatty acid synthase and the lipogenic phenotype in cancer pathogenesis. Nat Rev Cancer 7: 763-777, 2007.

7. Migita T, Ruiz S, Fornari A, Fiorentino M, Priolo C, Zadra G, Inazuka F, Grisanzio C, Palescandolo E, Shin E, et al: Fatty acid synthase: A metabolic enzyme and candidate oncogene in prostate cancer. J Natl Cancer Inst 101: 519-532, 2009.

8. Piyathilake CJ, Frost AR, Manne U, Bell WC, Weiss H, Heimburger DC and Grizzle WE: The expression of fatty acid synthase (FASE) is an early event in the development and progression of squamous cell carcinoma of the lung. Hum Pathol 31: 1068-1073, 2000

9. Swinnen JV, Roskams T, Joniau S, Van Poppel H, Oyen R, Baert L, Heyns W and Verhoeven G: Overexpression of fatty acid synthase is an early and common event in the development of prostate cancer. Int J Cancer 98: 19-22, 2002.

10. Innocenzi D, Alò PL, Balzani A, Sebastiani V, Silipo V, La Torre G, Ricciardi G, Bosman C and Calvieri S: Fatty acid synthase expression in melanoma. J Cutan Pathol 30: 23-28, 2003.

11. Omura S: The antibiotic cerulenin, a novel tool for biochemistry as an inhibitor of fatty acid synthesis. Bacteriol Rev 40: 681-697, 1976.

12. Pizer ES, Jackisch C, Wood FD, Pasternack GR, Davidson NE and Kuhajda FP: Inhibition of fatty acid synthesis induces programmed cell death in human breast cancer cells. Cancer Res 56: 2745-2747, 1996.

13. Zhao W, Kridel S, Thorburn A, Kooshki M, Little J, Hebbar S and Robbins M: Fatty acid synthase: A novel target for antiglioma therapy. Br J Cancer 95: 869-878, 2006.

14. Kuhajda FP, Pizer ES, Li JN, Mani NS, Frehywot GL and Townsend CA: Synthesis and antitumor activity of an inhibitor of fatty acid synthase. Proc Natl Acad Sci USA 97: 3450-3454, 2000.

15. Alli PM, Pinn ML, Jaffee EM, McFadden JM and Kuhajda FP: Fatty acid synthase inhibitors are chemopreventive for mammary cancer in $n e u-\mathrm{N}$ transgenic mice. Oncogene 24: 39-46, 2005.

16. Wang HQ, Altomare DA, Skele KL, Poulikakos PI, Kuhajda FP, Di Cristofano A and Testa JR: Positive feedback regulation between AKT activation and fatty acid synthase expression in ovarian carcinoma cells. Oncogene 24: 3574-3582, 2005.

17. Thupari JN, Pinn ML and Kuhajda FP: Fatty acid synthase inhibition in human breast cancer cells leads to malonyl-CoAinduced inhibition of fatty acid oxidation and cytotoxicity. Biochem Biophys Res Commun 285: 217-223, 2001.

18. Barger JF and Plas DR: Balancing biosynthesis and bioenergetics: Metabolic programs in oncogenesis. Endocr Relat Cancer 17: R287-R304, 2010.

19. Patel AV, Johansson G, Colbert MC, Dasgupta B and Ratner N: Fatty acid synthase is a metabolic oncogene targetable in malignant peripheral nerve sheath tumors. Neuro Oncol 17: 1599-1608, 2015

20. Bandyopadhyay S, Pai SK, Watabe M, Gross SC, Hirota S, Hosobe S, Tsukada T, Miura K, Saito K, Markwell SJ, et al: FAS expression inversely correlates with PTEN level in prostate cancer and a PI 3-kinase inhibitor synergizes with FAS siRNA to induce apoptosis. Oncogene 24: 5389-5395, 2005.

21. Zhang F and Du G: Dysregulated lipid metabolism in cancer. World J Biol Chem 3: 167-174, 2012.

22. Finck BN and Kelly DP: PGC-1 coactivators: Inducible regulators of energy metabolism in health and disease. J Clin Invest 116: 615-622, 2006.

23. Jiang WG, Douglas-Jones A and Mansel RE: Expression of peroxisome-proliferator activated receptor- $\gamma$ (PPARgamma) and the PPARgamma co-activator, PGC-1, in human breast cancer correlates with clinical outcomes. Int J Cancer 106: 752-757, 2003.

24. Watkins G, Douglas-Jones A, Mansel RE and Jiang WG: The localisation and reduction of nuclear staining of PPAR $\gamma$ and PGC-1 in human breast cancer. Oncol Rep 12: 483-488, 2004.

25. Feilchenfeldt J, Bründler MA, Soravia C, Tötsch $M$ and Meier CA: Peroxisome proliferator-activated receptors (PPARs) and associated transcription factors in colon cancer: Reduced expression of PPARgamma-coactivator 1 (PGC-1). Cancer Lett 203: 25-33, 2004. 
26. Zhang Y, Ba Y, Liu C, Sun G, Ding L, Gao S, Hao J, Yu Z, Zhang J, Zen K, et al: PGC-1 $\alpha$ induces apoptosis in human epithelial ovarian cancer cells through a PPAR $\gamma$-dependent pathway. Cell Res 17: 363-373, 2007.

27. Shiota M, Yokomizo A, Tada Y, Inokuchi J, Tatsugami K, Kuroiwa K, Uchiumi T, Fujimoto N, Seki N and Naito S: Peroxisome proliferator-activated receptor $\gamma$ coactivator- $1 \alpha$ interacts with the androgen receptor (AR) and promotes prostate cancer cell growth by activating the AR. Mol Endocrinol 24 114-127, 2010.

28. Shin SW, Yun SH, Park ES, Jeong JS, Kwak JY and Park JI: Overexpression of PGC-1 $\alpha$ enhances cell proliferation and tumorigenesis of HEK293 cells through the upregulation of $\mathrm{Sp1}$ and Acyl-CoA binding protein. Int J Oncol 46: 1328-1342, 2015.

29. Vock C, Biedasek K, Boomgaarden I, Heins A, Nitz I and Döring F: ACBP knockdown leads to down-regulation of genes encoding rate-limiting enzymes in cholesterol and fatty acid metabolism. Cell Physiol Biochem 25: 675-686, 2010.

30. Lee MY, Moon JS, Park SW, Koh YK, Ahn YH and Kim KS KLF5 enhances SREBP-1 action in androgen-dependent induction of fatty acid synthase in prostate cancer cells. Biochem J 417: 313-322, 2009.

31. Quah BJ, Warren HS and Parish CR: Monitoring lymphocyte proliferation in vitro and in vivo with the intracellular fluorescent dye carboxyfluorescein diacetate succinimidyl ester. Nat Protoc 2: 2049-2056, 2007.

32. Shin SW, Seo CY, Han H, Han JY, Jeong JS, Kwak JY and Park JI: $15 \mathrm{~d}-\mathrm{PGJ}{ }_{2}$ induces apoptosis by reactive oxygen species-mediated inactivation of Akt in leukemia and colorectal cancer cells and shows in vivo antitumor activity. Clin Cancer Res 15: 5414-5425, 2009.

33. Ishimura N, Amano Y, Sanchez-Siles AA, Fukuhara H, Takahashi Y, Uno G, Tamagawa Y, Mishima Y, Yuki T, Ishihara S, et al: Fatty acid synthase expression in Barrett's esophagus: Implications for carcinogenesis. J Clin Gastroenterol 45: 665-672, 2011.

34. Wellberg EA, Rudolph MC, Lewis AS, Padilla-Just N, Jedlicka P and Anderson SM: Modulation of tumor fatty acids, through overexpression or loss of thyroid hormone responsive protein spot 14 is associated with altered growth and metastasis. Breast Cancer Res 16: 481, 2014.
35. Yellen $P$ and Foster DA: Inhibition of fatty acid synthase induces pro-survival Akt and ERK signaling in K-Ras-driven cancer cells. Cancer Lett 353: 258-263, 2014.

36. Xiong S, Chirala SS and Wakil SJ: Sterol regulation of human fatty acid synthase promoter I requires nuclear factor-Y- and Sp-1-binding sites. Proc Natl Acad Sci USA 97: 3948-3953, 2000.

37. Summermatter S, Baum O, Santos G, Hoppeler H and Handschin C: Peroxisome proliferator-activated receptor \{gamma\} coactivator 1 alpha\} (PGC-1\{alpha\}) promotes skeletal muscle lipid refueling in vivo by activating de novo lipogenesis and the pentose phosphate pathway. J Biol Chem 285: 32793-32800, 2010.

38. Zaytseva YY, Elliott VA, Rychahou P, Mustain WC, Kim JT, Valentino J, Gao T, O'Connor KL, Neltner JM, Lee EY, et al: Cancer cell-associated fatty acid synthase activates endothelial cells and promotes angiogenesis in colorectal cancer. Carcinogenesis 35: 1341-1351, 2014.

39. Zaytseva YY, Rychahou PG, Gulhati P, Elliott VA, Mustain WC, O'Connor K, Morris AJ, Sunkara M, Weiss HL, Lee EY, et al: Inhibition of fatty acid synthase attenuates CD44-associated signaling and reduces metastasis in colorectal cancer. Cancer Res 72: 1504-1517, 2012.

40. Sounni NE, Cimino J, Blacher S, Primac I, Truong A, Mazzucchelli G, Paye A, Calligaris D, Debois D, De Tullio P, et al: Blocking lipid synthesis overcomes tumor regrowth and metastasis after antiangiogenic therapy withdrawal. Cell Metab 20: 280-294, 2014.

41. Seguin F, Carvalho MA, Bastos DC, Agostini M, Zecchin KG, Alvarez-Flores MP, Chudzinski-Tavassi AM, Coletta RD and Graner E: The fatty acid synthase inhibitor orlistat reduces experimental metastases and angiogenesis in B16-F10 melanomas. $\mathrm{Br}$ J Cancer 107: 977-987, 2012.

42. Chajès V, Cambot M, Moreau K, Lenoir GM and Joulin V: Acetyl-CoA carboxylase alpha is essential to breast cancer cell survival. Cancer Res 66: 5287-5294, 2006.

43. Bhalla K, Hwang BJ, Dewi RE, Ou L, Twaddel W, Fang HB, Vafai SB, Vazquez F, Puigserver P, Boros L, et al: PGC1a promotes tumor growth by inducing gene expression programs supporting lipogenesis. Cancer Res 71: 6888-6898, 2011. 